УДК $332.01,332.05$

DOI 10.52575/2687-0932-2021-48-1-44-58

\title{
Стратегия «умной специализации»: характерные признаки и условия успешной реализации в регионе
}

\author{
Шевченко С.А., Кузьмина Е.В., Кузьмина М.И. \\ Волгоградский государственный технический университет, \\ Россия, 400005, г. Волгоград, ул. Ленина, 75 \\ E-mail: svetashev@mail.ru
}

\begin{abstract}
Аннотация. Цель исследования - уточнение характерных признаков стратегии «умной специализации» и выявление условий её успешной реализации в регионе. В статье проанализированы подходы к определению стратегии «умной специализации» с позиции разных авторов и уточнены её характерные признаки (инновационный, диверсификационный и стратегический характер, уникальность, направленность на экономическое развитие территории региона, необходимость инвестиций и государственной поддержки при реализации стратегии, эффективное сотрудничество с другими регионами, взаимодействие между заинтересованными сторонами в направлении инновационной деятельности и другие). Определено, что основополагающими элементами стратегии «умной специализации» являются: инновации; государственная поддержка; межрегиональное сотрудничество; взаимодействие государство-бизнес-наука; предпринимательская инициатива; диверсификация региональной экономики, инвестиции для развития высокотехнологичных и наукоемких отраслей специализации; уникальные ресурсы региона. В статье уточнены предпосылки необходимости разработки и реализации стратегии «умной специализации» в регионе (усиление конкуренции на внутренних и внешних рынках; дефицит технологических, финансовых и других ресурсов, слабая степень процессов модернизации в промышленности; низкая доля вовлеченности академического сектора в процесс создания инноваций; слабая степень сетевого научного сотрудничества и другие) и предложены этапы разработки стратегии «умной специализации» в регионе. В ходе исследования были получены выводы о том, что к условиям успешной реализации стратегии «умной специализации» в регионе относятся: информационное освещение среди всех заинтересованных лиц; высокий уровень сотрудничества и доверия между государством, университетами и бизнесом; наличие коммерческой ценности и востребованности результатов научных исследований в регионе и вне его; положительный инвестиционный климат в регионе; стимулирование предпринимательской активности региона; наличие предпринимательских университетов как субъектов стимулирования инновационной деятельности для создания предпринимательской среды и другие.
\end{abstract}

Ключевые слова: регион, уникальные ресурсы региона, инновационные кластеры, предпринимательская инициатива, технологическая модернизация, государственная поддержка.

Для цитирования: Шевченко С.А., Кузьмина Е.В., Кузьмина М.И. 2021. Стратегия «умной специализации»: характерные признаки и условия успешной реализации в регионе. Экономика. Информатика, 48 (1): 44-58. DOI: 10.52575/2687-0932-2021-48-1-44-58.

\section{Strategy of «smart specialization»: characteristics and conditions for successful implementation in the region}

\author{
Svetlana A. Shevchenko, Ekaterina V. Kuzmina, Maria I. Kuzmina \\ Volgograd State Technical University, \\ 75 Lenin St, Volgograd, 400005, Russia \\ E-mail: svetashev@mail.ru
}

\begin{abstract}
The purpose of the study is to clarify the characteristic features of the "smart specialization" strategy and to identify the conditions for its successful implementation in the region. The article analyzes the approaches to defining the strategy of "smart specialization" from the standpoint of various authors and clarifies its characteristic features (innovative, diversified and strategic nature, uniqueness, focus on the economic development of the region's territory, the need for investment and state support in implementing the strategy,
\end{abstract}


effective cooperation with others regions, interaction between stakeholders in the direction of innovation, and others). It was determined that the fundamental elements of the smart specialization strategy are: innovation; governmental support; interregional cooperation; government-business science interaction; entrepreneurial initiative; diversification of the regional economy, investments for the development of high-tech and knowledge-intensive industries of specialization; unique resources of the region. The article clarifies the prerequisites for the need to develop and implement a smart specialization strategy in the region (increased competition in domestic and foreign markets; lack of technological, financial and other resources, a weak degree of modernization processes in industry; a low share of involvement of the academic sector in the process of creating innovations; weak the degree of network scientific cooperation and others) and the stages of developing a strategy of "smart specialization" in the region are proposed. In the course of the study, it was concluded that the conditions for the successful implementation of the "smart specialization" strategy in the region include: information coverage among all stakeholders; a high level of cooperation and trust between the state, universities and business; the presence of commercial value and relevance of the results of scientific research in the region and beyond; a positive investment climate in the region; stimulating entrepreneurial activity in the region; the presence of entrepreneurial universities as subjects of stimulating innovation to create an entrepreneurial environment, and others.

Keywords: region, unique resources of the region, innovation clusters, entrepreneurial initiative, technological modernization, government support.

For citation: Shevchenko S.A., Kuzmina E.V., Kuzmina M.I. 2021. Strategy of «smart specialization»: characteristics and conditions for successful implementation in the region. Economics. Information technologies, 48 (1): 44-58 (in Russian). DOI: 10.52575/2687-0932-2021-48-1-44-58.

\section{Введение}

На современном этапе развития экономики важное значение уделяется развитию регионов. Государством разрабатываются различные нормативные акты в этом направлении, где декларируются приоритеты развития регионов.

В 2019 году в России была утверждена «Стратегия пространственного развития Российской Федерации на период до 2025 года», в которой в качестве приоритетов выступают экономическое и социальное развитие регионов России на основе научных исследований и внедрения новых технологий [Стратегия пространственного развития Российской Федерации на период до 2025 года]. В документе подчеркивается, что конкурентоспособность регионов России должна быть обеспечена развитием приоритетных специализаций регионов на основе создания центров экономического роста. Формирование перспективных направлений специализации региона является важным фактором обеспечения экономического развития как территории региона, так и государства в целом.

Одним из инструментов формирования перспективных направлений специализации территории является стратегия «умной специализации», которая основывается на научноисследовательских разработках, технологическом обновлении и инновационном потенциале территории.

На современном этапе развития экономической науки стратегия «умной специализации» является объектом многочисленных научных исследований как в России, так и за рубежом.

Однако положительный практический опыт реализации стратегии «умной специализации» в большей степени представлен в зарубежных регионах. В России стратегия «умной специализации» только набирает обороты. В работах российских исследователей рассматриваются теоретические аспекты данного вопроса, которые включают выявление сущности понятия «умной специализации», особенности и условия использования стратегии «умной специализации», взаимосвязь с инновационными кластерами и другие. Также следует отметить, что в большинстве регионов России разработаны нормативные документы по реализации стратегии «умной специализации», что свидетельствует о перспективности данного направления для экономического и социального развития региона. 


\section{Основные результаты исследования}

Анализ научных экономических исследований показал, что «умная специализация» представляется в работах исследователей как концепция и как стратегия.

Тем не менее большинство авторов трактуют «умную специализацию» как стратегию инновационного развития территории.

Например, Г.И. Татенко связывает стратегию «умной специализации» с цифровой экономикой, полагая, что данная стратегия реализуется в условиях цифровой экономики и служит для создания новых направлений специализации региона. Автор отмечает диверсификационный характер стратегии и необходимость наличия предпринимательских возможностей [Татенко, 2019].

В региональном аспекте рассматривают стратегию «умной специализации» Э. Караяннис и Э. Григорудис, определяя ее как стратегию инновационной деятельности на региональном уровне. Авторы утверждают, что цель стратегии - обеспечение экономического роста региона и формирование его конкурентных преимуществ на основе инновационного потенциала с учетом потребностей бизнеса и тенденций внешней среды [Караяннис, Григорудис, 2016].

Такую особенность стратегии как концентрация ресурсов на приоритетных направлениях развития территории отмечают в своем исследовании О.В. Иншаков и Е.И. Иншакова. Авторы доказывают, к условиям эффективной реализации стратегии относятся: вовлечение предпринимательских структур, учреждений образования и науки в работу по выбору приоритетов развития территории, привлечение частных и государственных инвестиций и их рациональное использование [Иншаков, Иншакова, 2017].

В научных исследованиях прослеживается взаимосвязь стратегии «умной специализации» с кластерным подходом к экономическому развитию региона.

С.В. Кумакова в своей работе отмечает важную роль инновационных кластеров в реализации стратегии «умной специализации», которая заключается в формировании инновационного потенциала территории [Кумакова, 2019].

С позиции Е.В. Кузьминой, инновационный кластер - это совокупность организаций и предприятий различных организационно-правовых форм собственности, располагающихся на территории субъекта и осуществляющих взаимовыгодную деятельность, направленную на экономический рост как участников кластера, так и в целом территории региона. Значимость для развития экономики региона кластеров заключается в стимулировании инноваций в регионе, привлечении к ним представителей бизнеса и активизации производственного сектора экономики региона. Инновационный кластер позволяет решать финансовые, экономические, научные и социальные проблемы региона в условиях ограниченности ресурсов [Кузьмина, Шевченко, Кузьмина, 2020].

С.В. Кумакова выделяет условия развития инновационных кластеров в рамках стратегии «умной специализации». Инновационные кластеры должны: быть включены в формирование и реализацию региональной политики; инициировать инновационную деятельность в регионе; иметь свое место в стратегическом развитии региона; способствовать укреплению межрегиональных и межкластерных связей; использовать научный потенциал в рамках инновационных проектов и другие [Кумакова, 2019].

По мнению А.Н. Дырдоновой, роль инновационных кластеров в реализации стратегии «умной специализации» заключается в наличии знаний, инноваций и инвестиций для определения приоритетных областей специализации региона, которые будут обеспечивать экономический рост региона. Инновационные кластеры позволяют обеспечить региону степень оригинальности и специализации и как результат конкурентные преимущества по сравнению с другими регионами [Дырдонова, 2019].

В свою очередь «умная специализация» позволит инновационным кластерам эффективно использовать ресурсы и сосредоточить их на приоритетных направлениях развития территории региона. 
Экономическое развитие региона в долгосрочной перспективе обеспечивается конкурентными преимуществами региона, технологическими преобразованиями в промышленности, обновлениями факторов производства; эффективным взаимодействием с государством и бизнесом; привлечением инвестиций и другими факторами. Инновационные кластеры позволяют сформировать эти факторы для развития региона [Шевченко, Морозова, Кузьмина, Кузьмина, Минаева, 2020].

Особенно для развития экономики региона важны инновационно-производственные факторы, которые включают: модернизацию основных фондов и автоматизацию производственных процессов; снижение издержек производства; повышение производительности труда и качества продукции; повышение эффективности использования производственных ресурсов; снижение производственных рисков, в том числе связанных с человеческим фактором; расширение использования преимуществ инновационных технологий и другие [Морозова, Шевченко, Кузьмина, 2020].

В целом теоретический анализ научной экономической литературы дает нам основание заключить, что стратегия «умной специализации» способствует экономическому росту региона и имеет ряд характерных признаков.

К характерным признакам стратегии «умной специализации» относятся:

- инновационный характер стратегии, который проявляется в создании и реализации инноваций, в том числе через формирование и деятельность инновационных кластеров;

- уникальность стратегии, проявляющаяся в определении приоритетных отраслей специализации на основе накопленных ресурсов и компетенций территории;

- целенаправленность на экономическое развитие за счет формирования конкурентных преимуществ территории, основанных на собственном научном и инновационном потенциале;

- стратегический характер стратегии, проявляется в обеспечении долгосрочного эффекта экономического развития территории;

- предпринимательская инициатива, включающая предпринимательский поиск направлений специализации на основе потребностей общества, бизнеса и учета ресурсов территории;

- необходимость государственной поддержки в области создания условий для конкуренции, развития науки и образования, стимулирование спроса через систему закупок;

- диверсификационный характер стратегии, включающий расширение границ экономической активности территории в зависимости от конъюнктуры рынка и спроса;

- необходимость инвестиций (государственных и частных) для реализации научной и инновационной деятельности;

- эффективное сотрудничество с другими регионами с целью укрепления регионального потенциала и получение наибольшей отдачи от внешних технологий и возможностей;

- концентрация ресурсов на нескольких приоритетных и наиболее перспективных областях, обеспечивающих конкурентное преимущество экономики региона;

- взаимодействие между заинтересованными сторонами (государство, бизнес, общество и наука) в направлении формирования единого представления о направлениях достижения конкурентного преимущества региона.

Таким образом, основополагающими элементами стратегии «умной специализации» являются: инновации; государственная поддержка; межрегиональное сотрудничество; взаимодействие государство-бизнес-наука; предпринимательская инициатива; диверсификация региональной экономики, инвестиции для развития высокотехнологичных и наукоемких отраслей специализации; уникальные ресурсы региона.

Обратимся к практическому опыту реализации стратегии «умной специализации».

Практически во всех регионах России разработаны свои Концепции пространственного развития, в которых уделяется место стратегии «умной специализации». Следует отметить, что в целом такие стратегии содержательно очень похожи в своих приоритетных направлениях (поддержка инноваций, взаимодействие бизнеса, государства и науки, дея- 
тельность инновационных кластеров, предпринимательская инициатива и другие). Различие заключается в формировании отраслей специализации с учетом локальных условий конкретного региона.

Анализ научной экономической литературы показал малое количество научных исследований по описанию практического опыта реализации стратегии «умной специализации».

Об особенностях реализации стратегии «умной специализации» в регионах России можно судить в основном только с позиции изданных нормативных документов. Это свидетельствует о том, что опыт в этом направлении еще не накоплен.

Опыт реализации стратегии «умной специализации» имеется в Ульяновской области. В регионе в 2017 году была принята Концепция внедрения интеллектуальных цифровых технологий в Ульяновской области «Умный регион» на 2017-2030 годы. В данном документе определены основные приоритеты стратегии «умной специализации».

В частности, в Концепции определено понятие стратегии «умной специализации», связанное с выбором ограниченного числа приоритетных сфер. Основной акцент в реализации концепции «умной специализации» сделан на выявлении сильных сторон региона с учётом региональных особенностей и потребностей жителей региона и необходимости инвестиций. [Концепция внедрения интеллектуальных цифровых технологий в Ульяновской области «Умный регион» на 2017-2030 годы.]

Стратегия «умной специализации» основывается на взаимодействии государства, бизнес-сообщества и гражданского общества при реализации инновационных проектов, основах цифровой экономики и международном сотрудничестве в сфере развития ИКТ. В рамках стратегии «умной специализации» развиваются высокотехнологичные и наукоемкие отрасли, в результате чего увеличивается доля инновационных товаров, работ и услуг. Важную роль в реализации стратегии играют инновационные кластеры, которые позволяют привлечь дополнительные инвестиции в регион.

В Красноярском крае стратегия «умной специализации» сопровождается следующими действиями региональных властей: формирование точек экономического роста и инфраструктуры с использованием механизмов государственно-частного партнерства; использование налоговых механизмов, стимулирующих реализацию капиталоемких проектов; формирование системы подготовки квалифицированных кадров для приоритетных отраслей; стимулирование научной и инновационной деятельности посредством взаимодействия бизнеса с научными учреждениями [Стратегия социально-экономического развития Красноярского края до 2030 года].

Во многих других регионах России подготовлены свои Стратегии социальноэкономического развития на период до 2030 года. В данных стратегиях отражены такие особенности стратегии «умной специализации» как инновационный характер; взаимодействие всех заинтересованных лиц в рамках инновационной деятельности, стимулирование инвестиционной деятельности, формирование инновационных кластеров как точек экономического роста, развитие предпринимательской инициативы и другие.

В Самарской области Министерством экономического развития и инвестиций предпринимательская инициатива реализуется через различные программы для представителей бизнеса. Примером может служить программа «Школа чемпионов». Данная инициатива имеет целью привлечение бизнес-структур к разработке инноваций в регионе [Дмитриев, 2020].

Ожидаемыми результатами программы являются: сформированные у представителей бизнеса навыки в использовании инструментов цифровой трансформации для разработки инноваций; рост эффективности инновационных проектов на основе эффективного взаимодействия бизнеса, государства и экспертов; рост вовлеченности молодежи в осуществление инновационной деятельности; запуск стартапов.

В реализации стратегии «умной специализации» в регионах России важная роль отводится вузам, которые позволяют стимулировать предпринимательскую активность региона. 
Г.М. Самостроенко в своем исследовании доказывает, что на научную ориентацию вузов в регионе влияют ряд факторов, которые вузы не в полной мере используют. К таким факторам относятся следующие: возможности реализации инновационных разработок для промышленности региона; соотношение между направлениями исследования и получаемым доходом вуза; наличие связей с предприятиями региона в области научной деятельности; возможность экспорта научных знаний; востребованность конкретных направлений научных исследований у абитуриентов и студентов; другие [Самостроенко, 2019].

Г.М. Самостроенко в своей работе описывает опыт в реализации стратегии «умной специализации» вузов Орловской области. Приоритеты научных исследований (структурноаналитическая мезомеханика наноструктурных материалов и технологий, теория и принципы конструирования медицинских комплексов и оборудования, и другие) были определены в рамках приоритетных направлений научно-технологического развития России. Данные приоритеты были обусловлены наличием производственных предприятий в регионе; затратами на научные исследования и прибылью от них; востребованностью конкретных направлений научных исследований у абитуриентов и студентов.

Вузы Орловской области в направлении развития предпринимательской инициативы взаимодействуют с промышленными предприятиями через Фонд содействия развитию малых форм предприятий в научно-технической сфере.

В рамках этого взаимодействия можно выделить следующие приоритеты: создание высокотехнологичной продукции; получение коммерческой прибыли от реализации инновационной продукции; приток квалифицированных работников в высокотехнологическую сферу; привлечение инвестиций в сферу малого инновационного предпринимательства.

Вузы ориентируются в первую очередь на создание следующих условий для реализации стратегии «умной специализации»: коммерческая ценность и востребованность результатов научных исследований; учет запроса заинтересованных лиц (предприятия, госбюджетные организации, общество) на инновации, и необходимость проведения маркетинговых исследований с целью определения потребностей заинтересованных лиц; направленность научных разработок на практическое использование; привлечение студентов к научной деятельности и внедрение в вузе нового уровня системы обучения прикладного характера, при котором студенты решают задачи в интересах потенциального покупателя; создание творческих групп студентов разного профиля (технического, экономического и других) для работы над проектами для конкретного заказчика бизнес-сообщества или органов власти; финансирование научных исследований студентов со стороны бизнес-структур и государства.

На основе рассмотрения практики реализации стратегии «умной специализации» в некоторых наиболее продвинутых регионах России можно выделить некоторые особенности данной стратегии в регионах России (табл. 1).

Таблица 1 Table 1

Особенности реализации стратегии «умной специализации» в регионах России Features of the implementation of the smart specialization strategy in the regions of Russia

\begin{tabular}{|l|l|}
\hline Регион России & \multicolumn{1}{|c|}{ Особенности реализации стратегии «умной специализации» } \\
\hline Ульяновская об- & - Выбор приоритетных отраслей региона на основе сильных сторон региона с \\
лаётом региональных особенностей и потребностей жителей региона; & - создание инновационных кластеров для реализации инновационных проектов; \\
& - работа по привлечению инвестиций в регион для развития высокотехнологич- \\
& ных и наукоемких отраслей и увеличения доли инновационных товаров, работ и \\
& услуг; \\
& - осуществление взаимодействия государства, бизнеса и гражданского общества \\
& при реализации инновационных проектов; \\
& - осуществление международного сотрудничества для целей экономического ро- \\
& ста региона. \\
\hline
\end{tabular}


Окончание табл. 1

\begin{tabular}{|c|c|}
\hline 1 & 2 \\
\hline $\begin{array}{l}\text { Красноярский } \\
\text { край }\end{array}$ & $\begin{array}{l}\text { - Формирование точек экономического роста и инфраструктуры в рамках прио- } \\
\text { ритетных отраслей специализации; } \\
\text { - государственная поддержка за счет использования налоговых механизмов, сти- } \\
\text { мулирующих реализацию капиталоемких проектов; } \\
\text { - стимулирование научной и инновационной деятельности в регионе; } \\
\text { - осуществление взаимодействия государства и бизнеса через механизм государ- } \\
\text { ственно-частного партнерства; } \\
\text { - формирование системы подготовки квалифицированных кадров для приори- } \\
\text { тетных отраслей; } \\
\text { - взаимодействие бизнеса с научными учреждениями региона. }\end{array}$ \\
\hline $\begin{array}{l}\text { Самарская } \\
\text { ласть }\end{array}$ & $\begin{array}{l}\text { - Развитие инновационной деятельности в регионе за счет привлечения бизнес- } \\
\text { структур к разработке инноваций; } \\
\text { - организация эффективного взаимодействия бизнеса, государства; } \\
\text { - осуществление работы по вовлеченности молодежи в осуществление инно- } \\
\text { вационной деятельности в регионе; } \\
\text { - создание новых предпринимательских организаций-стартапов. }\end{array}$ \\
\hline $\begin{array}{l}\text { Орловская } \\
\text { ласть }\end{array}$ & $\begin{array}{l}\text { - Стимулирование предпринимательской активности региона на основе взаимо- } \\
\text { действия с вузами региона; } \\
\text { - организация научных исследований в рамках приоритетных направлений науч- } \\
\text { но-технологического развития России; } \\
\text { - стимулирование притока квалифицированных работников в высокотехнологи- } \\
\text { ческие отрасли региона; } \\
\text { - организация взаимодействия вузов и промышленных предприятий с целью полу- } \\
\text { чения коммерческой прибыли от реализации инновационной продукции; } \\
\text { - привлечение инвестиций в сферу малого инновационного предприниматель- } \\
\text { ства. }\end{array}$ \\
\hline
\end{tabular}

Обратимся к успешному практическому опыту реализации стратегии «умной специализации» в зарубежных регионах.

Опыт реализации стратегии «умной специализации» в Республике Молдова описывает в своем исследовании Л.А. Шавга. Реализация стратегии «умной специализации» в Республике Молдова началась с 2016 года и была обусловлена наличием следующих предпосылок: усилением конкуренции на внутренних и внешних рынках, снижением показателей экономического развития территории Республики Молдова, проблемы с внедрением научной и инновационной деятельности в сферу производства; слабое государственное финансирование научных разработок; отсутствие взаимосвязи между содержанием стратегических документов региона и локальными условиями и другие [Шавга, 2020].

Реализация стратегии «умной специализации» осуществлялась через ряд этапов: повышение осведомленности общества о стратегии «умной специализации» и её влиянии на экономическое развитие (через проведение различных семинаров); анализ научного, инновационного и экономического потенциала Республики Молдова (выявление сильных сторон и возможностей для инноваций для приоритетов «умной специализации»); определение приоритетных отраслей для стратегии «умной специализации» с учетом экономического потенциала (разделение на отрасли с приоритетами, ориентированными на науку; на технологии и инновации); определение сфер предпринимательской деятельности для приоритетных отраслей стратегии «умной специализации» (проведение семинаров по предпринимательскому поиску); разработка региональной политики с учетом стратегии «умной специализации» и выбор эффективных инструментов для достижения целей.

Особое место в региональной инновационной политике должна занимать стратегия «умной специализации», которая может включать ряд инновационных стратегий, основанных на конкурентных преимуществах региона в области научно-технологической сферы и с учетом потребностей бизнеса. В рамках инновационных стратегий должны осуществлять свою деятель- 
ность инновационные кластеры в сотрудничестве с производственным сектором. Именно инновационные кластеры позволят инициировать позитивные структурные изменения в экономике региона [Хмелева, Королева, Курникова, 2019].

Начальными результатами реализации стратегии «умной специализации» явились: позитивные процессы экономических преобразований в регионах Республики Молдова на основе эффективного использования инновационного потенциала и осуществление взаимовыгодного сотрудничества государства, бизнеса и науки.

А. Бош и Н. Вонортас в своей работе обобщили опыт Бразилии в реализации стратегии «умной специализации». К необходимости внедрения стратегии «умной специализации» привели следующие причины: наличие барьеров в реализации инновационной деятельности; слабая степень сетевого научного сотрудничества в регионе; высокая степень централизации инновационной системы страны; высокая доля неконкурентоспособных исследований в частном секторе; слабая вовлеченность академического сектора в процесс создания инноваций; конкуренция между образовательной, научно-исследовательской и производственной подсистемами и другие [Бош, Вонортас, 2019].

Цель стратегии «умной специализации» - это устранение барьеров для инновационной деятельности и структуризация региональной инновационной политики. Стратегия «умной специализации» в Бразилии реализуется через этапы, которые включают: анализ экономического потенциала региона, выявление конкурентных преимуществ; определение приоритетов для политических инициатив; принятие согласованной долгосрочной стратегии по повышению конкурентоспособности и устойчивости экономики региона. Значимая роль в реализации стратегии отводится опорным институтам, каждый из которых относится к определённому компоненту развитой и разветвленной инновационной системы.

Стратегия «умной специализации» в Бразилии непосредственно связана с деятельностью инновационных кластеров. Инновационные кластеры объединяют компании, расположенные в одном регионе и которые координируются общим направлением специализации. Компании взаимодействуют с региональными властями, научными институтами, бизнесассоциациями и финансирующими организациями.

Преимуществами кластеров являются: экономический эффект за счет экономии от масштаба; повышение качества продукции и производительности труда; снижение рисков и оптимизация финансовых затрат при осуществлении инновационных проектов; создание условий для обмена опытом и наращивания инновационного потенциала; выявление новых наукоемких направлений для трансформации региональной экономики.

К основным препятствиям в реализации стратегии «умной специализации» в Бразилии можно отнести: ограниченные ресурсы человеческого и технологического капитала в государственном и частном секторах; низкий уровень сотрудничества и доверия между государством, университетами и бизнесом; слабое информационное освещение результатов инициатив инновационной политики, особенно на региональном уровне; недостаточность финансовых ресурсов для реализации стратегий развития научной сферы и другие.

Проблемы реализации стратегии «умной специализации» в европейских странах связаны с цифровыми компетенциями государственных органов. Например, в Латвии существует проблема осуществления научно-исследовательской деятельности с использованием цифровых технологий, что не позволяет осуществить непрерывную обработку результатов исследований [Reid, 2018, Rainoldi, 2018]. В Румынии существует проблема привлечения стейкхолдеров в инновационную деятельность. В Ирландии при переходе к стратегии «умной специализации» регионы подвержены влиянию политических партий [Ranga, 2018].

Опыт Республики Казахстан представлен в работе Н.К. Нурлановой. К необходимости разработки стратегии «умной специализации» в Республике Казахстан привели следующие обстоятельства: нерациональная региональная структура экономики (разнородность регионов по экономическому развитию; высокая экономическая дифференциация промышленного производства в регионах; низкий уровень государственного и частного финансирования научно-исследовательской деятельности; снижение эффективности человеческого капитала и 
как следствие формирование новых знаний; преобладание в регионах процессов заимствования инноваций, а не создания собственных инноваций, в результате чего снижается спрос на продукцию новых производств и влияние «точек роста» на слабые регионы; слабая степень влияния регионов-лидеров на экономический рост отсталых регионов; слабые стимулирующие меры региональной политики, направленные на инновационное развитие экономики регионов; дефицит трудовых, технологических, финансовых и других ресурсов регионов. В результате действие всех факторов привело к снижению экономического роста Республики Казахстан [Нурланова, 2019].

Первоначально планировалось, что цель стратегии «умной специализации» - распространение потенциала ведущих отраслей на отсталые регионы. Стратегия «умной специализации» включала следующие мероприятия: технологическая модернизация в отстающих регионах; поиск «точек роста» как центров модернизации, индустриального и постиндустриального развития («точки роста» - взаимосвязанные города, которые обладают конкурентными преимуществами), которые будут за счет производства инноваций стимулировать развитие отсталых регионов; разработка сценариев реализации стратегии на основе дифференцированного подхода к пространственному развитию; развитие прочных экономических связей между регионами.

Технологическая модернизация Республики Казахстан осуществлялась в рамках стратегических направлений: стимулирование инновационного предпринимательства в направлении создания новых рынков продукции и услуг; стимулирование предпринимательской активности в отношении сетевых взаимодействий (государство, бизнес, общество, наука); активизация человеческого капитала на территории Республики Казахстан и повышение эффективности его использования с аспекта создания новых знаний; использование механизмов политики опережающего развития городов, выбранных в качестве «точек роста», и поддержка их со стороны государства (государственные программы, введение особых режимов хозяйствования, формирование инвестиционного климата, развитие городской инфраструктуры, укрепление человеческого потенциала и другие); создание предпринимательских университетов как субъектов стимулирования инновационной деятельности и создания предпринимательской среды, деятельность которых будет связана с выполнением фундаментальных и прикладных научно-исследовательских проектов по созданию малых инновационных компаний.

Были разработаны три сценария реализации стратегии в зависимости от уровня инновационного потенциала региона. Для регионов с высоким уровнем инновационного потенциала: создание кластерных зон с опорой на центр инноваций с эффективной системой стимулирования научно-исследовательской деятельности и государственной поддержкой. Ожидаемый результат - повышение спроса на новые научные и инженерные кадры, формирование развитой инновационной системы. Для регионов со средним уровнем инновационного потенциала: развитие базовых отраслей, обновление отечественных технологий и переустройства экономики регионов за счет использования иностранных технологий. Для регионов с низким уровнем инновационного потенциала: создание благоприятных условий для обеспечения технологического обновления традиционных отраслей и формирования новых эффективных отраслей и производств при наличии государственной поддержки. Очевидно, что первый сценарий позволит сформировать «точки роста», которые будут оказывать влияние на развитие других регионов.

Особенности стратегии «умной специализации» в зарубежных регионах имеют свою специфику (табл. 2).

Таким образом, на примерах практического опыта реализации стратегии «умной специализации» можно сделать следующие выводы:

- практический опыт реализации стратегии «умной специализации» имеет место быть как в российских регионах, так и за рубежом;

- в российских регионах данный процесс на начальной стадии - разработке нормативных документов в этом направлении, а также имеют место быть отдельные элементы страте- 
гии «умной специализации» (формирование предпринимательской инициативы, формирование опорных вузов для осуществления научной деятельности и другие);

- наиболее информативен зарубежный практический опыт реализации стратегии «умной специализации», который позволяет уточнить: 1) предпосылки необходимости разработки и реализации стратегии «умной специализации»; 2) этапы разработки стратегии «умной специализации»; 3) условия успешной реализации стратегии «умной специализации»;

- анализ практического опыта подтверждает особенности стратегии «умной специализации», выявленные в статье выше (уникальность стратегии, целенаправленность на экономическое развитие, наличие эффективного сотрудничества с другими регионами с целью укрепления регионального потенциала; приоритеты инновационной деятельности; предпринимательская инициатива и другие).

Таблица 2

Table 2

Особенности реализации стратегии «умной специализации» в зарубежных регионах и странах

Features of the implementation of the smart specialization strategy in foreign regions and countries

\begin{tabular}{|c|c|}
\hline ГИОН & енности реализации стратегии «умной специализации» \\
\hline $\begin{array}{l}\text { Республика } \\
\text { Молдова }\end{array}$ & $\begin{array}{l}\text { - наличие этапов реализации стратегии; } \\
\text { - проведение семинаров для общества с целью повышения его осведомленности о } \\
\text { создании и реализации стратегии «умной специализации» и её влиянии на экономи- } \\
\text { ческое развитие республики; } \\
\text { - определение приоритетных отраслей специализации республики на основе эконо- } \\
\text { мического потенциала территории; } \\
\text { - создание инновационных кластеров с целью развития инновационной деятельно- } \\
\text { сти и инициирования структурных изменений в отраслевой структуре республики; } \\
\text { - организация сотрудничества государства, бизнеса и науки в области инновацион- } \\
\text { ного и научно-технологического развития республики. }\end{array}$ \\
\hline Бразилия & $\begin{array}{l}\text { - наличие этапов реализации стратегии; } \\
\text { - развитие опорных университетов как основы инновационной деятельности; } \\
\text { - создание инновационных кластеров (которые объединяют компании, расположен- } \\
\text { ные в одном регионе, и координируются общим направлением специализации) для } \\
\text { выявления новых наукоемких направлений для трансформации региональной эко- } \\
\text { номики; } \\
\text { - организация взаимодействия региональных властей, научных институтов, бизнес- } \\
\text { ассоциаций и финансовых организаций; } \\
\text { - межрегиональное взаимодействие с целью обмена опытом и наращивания иннова- } \\
\text { ционного потенциала региона. }\end{array}$ \\
\hline $\begin{array}{l}\text { Республика } \\
\text { Казахстан }\end{array}$ & $\begin{array}{l}\text { - технологическая модернизация в отстающих регионах; } \\
\text { - определение на территории региона «точек роста»- территорий, где будут созда- } \\
\text { ваться инновации, что будет способствовать стимулированию развития отсталых } \\
\text { регионов; } \\
\text { - разработка сценариев реализации стратегии на основе дифференцированного под- } \\
\text { хода к пространственному развитию и в зависимости от уровня инновационного } \\
\text { потенциала региона; } \\
\text { - развитие межрегионального сотрудничества; } \\
\text { - стимулирование предпринимательской активности в отношении сетевых взаимо- } \\
\text { действий государство-бизнес-общество-наука; } \\
\text { - создание условий для развития человеческого капитала и повышение эффективно- } \\
\text { сти его использования с аспекта создания новых знаний; } \\
\text { - стимулирование инновационной деятельности на основе создания предпринима- } \\
\text { тельских университетов; } \\
\text { - разработка и реализация научно-исследовательских проектов по созданию малых } \\
\text { инновационных компаний. }\end{array}$ \\
\hline
\end{tabular}




\section{Заключение}

Научный интерес к стратегии «умной специализации» с каждым годом растет. Стратегия «умной специализации» является объектом многочисленных научных экономических исследований. Актуальность темы прежде всего обусловлена и практической значимостью для экономического развития регионов.

Стратегия «умной специализации» имеет следующие характерные признаки: инновационный, диверсификационный и стратегический характер, уникальность, целенаправленность на экономическое развитие территории, предпринимательский поиск направлений специализации, необходимость инвестиций и государственной поддержки, эффективное сотрудничество с другими регионами, взаимодействие между заинтересованными сторонами в направлении инновационной деятельности и другие.

Обобщение практического опыта в направлении реализации стратегии «умной специализации» позволило нам уточнить предпосылки необходимости разработки и реализации стратегии «умной специализации» в регионе:

- в области конкуренции на рынках - усиление конкуренции на внутренних и внешних рынках; конкуренция между образовательной, научно-исследовательской и производственной подсистемами региона;

- в области ресурсов - дефицит технологических, финансовых и других ресурсов регионов; снижение эффективности человеческого капитала и как следствия формирования новых знаний;

- в области производственной деятельности - слабая степень внедрения научных разработок в сферу производства; слабая степень процессов модернизации в промышленности; высокая экономическая дифференциация промышленного производства в регионах;

- в области реализации инноваций - высокая степень централизации инновационной системы региона и низкая доля вовлеченности академического сектора в процесс создания инноваций; слабая степень сетевого научного сотрудничества в регионе; высокая доля неконкурентоспособных исследований в частном секторе;

- в области государственной поддержки - низкий уровень государственного и частного финансирования научно-исследовательской деятельности;

- в области региональной политики - отсутствие взаимосвязи между содержанием стратегических документов региона и локальными условиями региона; нерациональная региональная структура экономики (разнородность регионов по экономическому развитию); слабая степень влияния регионов-лидеров на экономический рост отсталых регионов; слабые стимулирующие меры региональной политики, направленные на инновационное развитие экономики регионов.

При разработке и реализации стратегии «умной специализации» можно выделить несколько этапов:

- повышение осведомленности заинтересованных лиц региона о стратегии «умной специализации» и её влиянии на экономическое развитие (через проведение различных семинаров);

- анализ экономического потенциала региона, выявление конкурентных преимуществ для реализации стратегии «умной специализации»;

- определение приоритетных отраслей для стратегии «умной специализации» с учетом экономического потенциала;

- определение сфер предпринимательской деятельности для формирования приоритетных отраслей, развитие предпринимательской активности в регионе через проведение различных мероприятий по разработке инноваций;

- технологическая модернизация в производстве в направлении создания новых рынков продукции и услуг;

- поиск «точек роста» как центров модернизации и индустриального развития, которые обладают конкурентными преимуществами и будут за счет производства инноваций и сотрудничества стимулировать развитие отсталых регионов; 
- создание предпринимательских университетов как субъектов стимулирования инновационной деятельности и создания предпринимательской среды в регионе;

- разработка и принятие согласованной долгосрочной региональной политики, в которой особое место отводится стратегии «умной специализации» с участием государства, бизнеса, общества и науки.

К условиям успешной реализации стратегии «умной специализации» в регионах с нашей точки зрения относятся:

- информационное освещение стратегии «умной специализации» в регионах среди всех заинтересованных лиц;

- наличие коммерческой ценности и востребованности результатов научных исследований в регионе и вне его;

- получение коммерческой прибыли от реализации инновационной продукции; бизнесом;

- высокий уровень сотрудничества и доверия между государством, университетами и

- наличие программ повышения квалификации работников в высокотехнологических сферах производства;

- положительный инвестиционный климат;

- возможности привлечения инвестиций в сферу малого инновационного предпринимательства;

- стимулирование предпринимательской активности региона; наличие предпринимательских университетов как субъектов стимулирования инновационной деятельности для создания предпринимательской среды;

- наличие технологических, финансовых и других ресурсов регионов;

- поддержка их со стороны государства «точек экономического роста» как центров модернизации и индустриального развития;

- использование инструментов: инновационные кластеры (для привлечения дополнительных инвестиций в регион); государственно-частное партнерство (для формирования точек экономического роста и инфраструктуры); налоговые механизмы, стимулирующие реализацию капиталоемких проектов; сетевое взаимодействие государства, бизнеса, общества и науки при реализации инновационных проектов.

\section{Список источников}

1. Концепция внедрения интеллектуальных цифровых технологий в Ульяновской области «Умный регион» на 2017-2030 годы. Официальный сайт Фонда развития информационных технологий Ульяновской области. URL: https://it-fund73.ru/ www.ulsmartregion / Koncept.php (дата обращения: 28 сентября 2020).

2. Стратегия социально-экономического развития Красноярского края до 2030 года. Официальный портал Красноярского края URL: http://www.krskstate.ru/2030/plan (дата обращения: 28 сентября 2020).

3. «Стратегия пространственного развития Российской Федерации на период до 2025 года». Официальный портал Министерства экономического развития Российской Федерации. URL:https://www.economy.gov.ru/material/directions/regionalnoe_razvitie/strategicheskoe_planirovanie_pr ostranstvennogo_razvitiya/strategiya_prostranstvennogo_razvitiya_rossiyskoy_federacii_na_period_do_202 5_goda/(дата обращения: 28 сентября 2020).

4. Дмитриев О. 2020. В Самарской области бизнес научат работать с инновациями. Российская газета. URL: https:// www.rg.ru/2020/09/15/reg-pfo/v-samarskoj-oblasti-biznes-nauchatrabotat-s-innovaciiami.html (дата обращения: 28 сентября 2020).

\section{Список литературы}

1. Бош А., Вонортас Н. 2019. «Умная специализация» как стимул инновационной экономики в развивающихся странах. Уроки Бразилии. Форсайт, 1: 32-47.

2. Дырдонова А.Н. 2019. Устойчивое развитие инновационных промышленных кластеров в рамках концепции умной специализации. В кн.: Высокие технологии и инновации в науке. 
Материалы международной научной конференции (Санкт-Петербург, 27 сентября 2019 г.). СанктПетербург, Изд-во СПбГУ: 197-201.

3. Иншаков О.В., Иншакова Е. И. 2017. Кластерное развитие Российской наноиндустрии как стратегический компонент «умной специализации» регионов. Региональная экономика. Юг России, 4: 4-10.

4. Караяннис Э., Григорудис Э. 2016. Четырехзвенная спираль инноваций и «умная специализация»: производство знаний и национальная конкурентоспособность. Форсайт, 1 :31-42.

5. Кузьмина Е.В., Шевченко С.А., Кузьмина М.И., Минаева О.А. 2020.Устойчивое развитие регионов на основе формирования инновационных кластеров. Экономика и предпринимательство, 4 : 300-303.

6. Кумакова С. В. 2019. Инновационные кластеры как механизм проектной реализации стратегии развития региона в рамках умной специализации. В кн.: Модернизация России: приоритеты. проблемы, решения. Материалы международной практической конференции (Москва, 20-21 декабря 2018 г.).Москва, Изд-во Институт научной информации по общественным наукам PAH: 825-830.

7. Морозова И.А., Шевченко С.А., Кузьмина Е.В. 2020. Исследование основных факторов устойчивости пространственного развития территорий с позиции системного подхода. Экономика устойчивого развития, 3: 76-83.

8. Нурланова Н.К. 2018. Технологическая модернизация экономики Регионов Казахстана на основе SMART специализации: сценарии и механизмы реализации. В кн.: Проблемы стратегического проектирования социально-экономического развития России. Материалы конференции по проблемам стратегического проектирования социально-экономического развития России (Москва, 01января - 01 мая 2018). Москва, Изд-во Институт научной информации по общественным наукам РАН: 1024-1028.

9. Самостроенко Г.М. 2019. Стратегии «умной специализации» регионального развития. В кн.: Регионы России: стратегии, механизмы модернизации, инновационного и технологического развития. Материалы международной научно-практической конференции (Москва, 06-07 июня 2019 г.). Москва, Изд-во Институт научной информации по общественным наукам РАН: 933-935.

10.Татенко Г. И. 2019. Концептуальные положения по управлению развитием территории. Управленческий учет, 9: 97-106.

11.Хмелева Г.А., Королева Е.Н., Курникова М.В2019. Стратегия "умной специализации": европейский опыт и уроки для России. Вестник Самарского муниципального института управления, 3: $35-45$.

12.Шавга Л.А., Баран Т.В. 2020. Внедрение концепции умной специализации катализатор экономического развития республики Молдова. Вестник Белгородского университета кооперации, экономики и права, $3: 50-53$

13.Шевченко С.А., Морозова И.А., Кузьмина Е.В., Кузьмина М.И., Минаева О.А. 2020. Управление устойчивым развитием экономики региона. Экономика и предпринимательство, 3 : 300-304.

14.Reid A., Stanovnik P. 2013. The Development of a Smart Specialisation Strategy for Slovenia: Report to the European Commission. Brussels: EC, Directorate General Research and Innovation.

15.Rainoldi A. 2018. 4 years of smart specialisation: lessons learned and plans for the future // www. Smart specialisation: progress and future prospects. Vilnius, 22 October 2018. URL: https:// www.mosta.lt/lt/renginiai/470-smart-specialisationprogress-and-future-prospects.

16.Ranga M. 2018. Smart specialization as a strategy to develop early-stage regional innovation systems. European Planning Studies, 26 (11): 2125-2146.

\section{References}

1. Bosh A., Vonortas N. 2019. «Umnaya spetsializatsiya» kak stimul innovatsionnoy ekonomiki v razvivayushchikhsya stranakh ["Smart specialization" as an incentive for innovative economy in developing countries]. Uroki Brazilii. Forsayt, 1: 32-47.

2. Dyrdonova A.N. 2019. Ustoychivoe razvitie innovatsionnykh promyshlennykh klasterov v ramkakh kontseptsii umnoy spetsializatsii [Sustainable development of innovative industrial clusters within the framework of the smart specialization concept]. V kn.: Vysokie tekhnologii i innovatsii v nauke [In: High Technologies and Innovations in Science]. Materialy mezhdunarodnoy nauchnoy konferentsii (Sankt-Peterburg, 27 sentyabrya 2019 g.). Sankt-Peterburg, Izd-vo SPbGU: 197-201. (in Russian)

3. Inshakov O.V., Inshakova E. I. 2017. Klasternoe razvitie Rossiyskoy nanoindustrii kak strategicheskiy komponent «umnoy spetsializatsii» regionov [Cluster development of the Russian 
nanoindustry as a strategic component of the "smart specialization" of the regions]. Regional'naya ekonomika. Yug Rossii, 4: 4-10. (in Russian)

4. Karayannis E., Grigorudis E. 2016. Chetyrekhzvennaya spiral' innovatsiy i «umnaya spetsializatsiya»: proizvodstvo znaniy i natsional'naya konkurentosposobnost' [The four-step spiral of innovation and "smart specialization": knowledge production and national competitiveness]. Forsayt, $1: 31-42$. (in Russian)

5. Kuz'mina E.V., Shevchenko S.A., Kuz'mina M.I., Minaeva O.A. 2020. Ustoychivoe razvitie regionov na osnove formirovaniya innovatsionnykh klasterov [Sustainable development of regions based on the formation of innovation clusters]. Ekonomika i predprinimatel'stvo, 4: 300-303. (in Russian)

6. Kumakova S. V. 2019. Innovatsionnye klastery kak mekhanizm proektnoy realizatsii strategii razvitiya regiona $\mathrm{v}$ ramkakh umnoy spetsializatsii [Innovation clusters as a mechanism for project implementation of the regional development strategy within the framework of smart specialization]. V kn.: Modernizatsiya Rossii: prioritety. problemy, resheniya [In: Modernization of Russia: Priorities. problems, solutions]. Materialy mezhdunarodnoy prakticheskoy konferentsii (Moskva, 20-21 dekabrya 2018 g.). Moskva, Izd-vo Institut nauchnoy informatsii po obshchestvennym naukam RAN: 825-830. (in Russian)

7. Morozova I.A., Shevchenko S.A., Kuz'mina E.V. 2020. Issledovanie osnovnykh faktorov ustoychivosti prostranstvennogo razvitiya territoriy s pozitsii sistemnogo podkhoda The study of the main factors of the stability of the spatial development of territories from the point of view of the system approach]. Ekonomika ustoychivogo razvitiya, 3: 76-83. (in Russian)

8. Nurlanova N.K. 2018. Tekhnologicheskaya modernizatsiya ekonomiki Regionov Kazakhstana na osnove SMART spetsializatsii: stsenarii i mekhanizmy realizatsii [Technological modernization of the economy of the Regions of Kazakhstan based on SMART specialization: scenarios and implementation mechanisms]. V kn.: Problemy strategicheskogo proektirovaniya sotsial'no-ekonomicheskogo razvitiya Rossii. Materialy konferentsii po problemam strategicheskogo proektirovaniya sotsial'no-ekonomicheskogo razvitiya Rossii [In: Problems of strategic design of socio-economic development of Russia] (Moskva, 01 yanvarya - 01 maya 2018). Moskva, Izd-vo Institut nauchnoy informatsii po obshchestvennym naukam RAN:1024-1028. (in Russian)

9. Samostroenko G.M. 2019. Strategii «umnoy spetsializatsii» regional'nogo razvitiya [Strategies for "smart specialization" of regional development]. V kn.: Regiony Rossii: strategii, mekhanizmy modernizatsii, innovatsionnogo i tekhnologicheskogo razvitiya [In: Regions of Russia: strategies, mechanisms of modernization, innovation and technological development]. Materialy mezhdunarodnoy nauchno-prakticheskoy konferentsii (Moskva, 06-07 iyunya 2019 g.). Moskva, Izd-vo Institut nauchnoy informatsii po obshchestvennym naukam RAN: 933-935. (in Russian)

10.Tatenko G. I. 2019. Kontseptual'nye polozheniya po upravleniyu razvitiem territorii. Upravlencheskiy uchet [Conceptual provisions for managing the development of the territory. Management accounting], 9: 97-106. (in Russian)

11.Khmeleva G.A., Koroleva E.N., Kurnikova M.V. 2019. Strategiya "umnoy spetsializatsii": evropeyskiy opyt i uroki dlya Rossii [Smart Specialization Strategy: European experience and lessons for Russia]. Vestnik Samarskogo munitsipal'nogo istituta upravleniya, 3: 35-45. (in Russian)

12.Shavga L.A., Baran T.V. 2020.Vnedrenie kontseptsii umnoy spetsializatsiikatalizator ekonomicheskogo razvitiya respubliki Moldova [The introduction of the concept of smart specialization is a catalyst for the economic development of the Republic of Moldova]. Vestnik Belgorodskogo universiteta kooperatsii, ekonomiki i prava, $3: 50-53$. (in Russian)

13.Shevchenko S.A., Morozova I.A., Kuz'mina E.V., Kuz'mina M.I., Minaeva O.A. 2020. Upravlenie ustoychivym razvitiem ekonomiki regiona Managing the sustainable development of the region's economy]. Ekonomika i predprinimatel'stvo, 3: 300-304. (in Russian)

14.Reid A., Stanovnik P. 2013. The Development of a Smart Specialization Strategy for Slovenia: Report to the European Commission. Brussels: EC, Directorate General Research and Innovation.

15.Rainoldi A. 2018. 4 years of smart specialization: lessons learned and plans for the future // Smart specialization: progress and future prospects. Vilnius, 22 October 2018. URL: https://mosta.lt/lt/renginiai/470-smart-specialisationprogress-and-future-prospects.

16.Ranga M. 2018. Smart specialization as a strategy to develop early-stage regional innovation systems. European Planning Studies, 26 (11): 2125-2146. 


\section{ИНФОРМАЦИЯ ОБ АВТОРАХ}

Шевченко Светлана Алексеевна, кандидат педагогических наук, доцент, доцент кафедры экономики и предпринимательства Волгоградского государственного технического университета, Волгоград, Россия

Кузьмина Екатерина Валериевна, кандидат экономических наук, доцент, доцент кафедры экономики и предпринимательства Волгоградского государственного технического университета, Волгоград, Россия

Кузьмина Мария Игоревна, кандидат экономических наук, доцент, доцент кафедры экономики и предпринимательства Волгоградского государственного технического университета, Волгоград, Россия
INFORMATION ABOUT THE AUTHORS

Svetlana A. Shevchenko, Candidate Pedagogical Sciences, Assistant Professor, Associate Professor of the Department of Economics and Entrepreneurship Volgograd State Technical University, Volgograd, Russia

Ekaterina V. Kuzmina, Candidate Economic Sciences, Assistant Professor, Associate Professor of the Department of Economics and Entrepreneurship Volgograd State Technical University, Volgograd, Russia

Maria I. Kuzmina, Candidate Economic Sciences, Assistant Professor, Associate Professor of the Department of Economics and Entrepreneurship Volgograd State Technical University, Volgograd, Russia 